\title{
Exploring the bifurcation between sedimentation versus scour onset below pipelines in unidirectional currents
}

\author{
T. Griffiths ${ }^{(1,2)}$, S. Draper ${ }^{(1,2)}$, W. Sun ${ }^{(2)}$, D. White ${ }^{(1,2)}$, L. Cheng ${ }^{(2)} \&$ H. An ${ }^{(2)}$ \\ (1) Centre for Offshore Foundation Systems, University of Western Australia, Perth Australia \\ (2) School of Civil, Environmental and Mining Engineering, University of Western Australia, Perth Australia
}

\begin{abstract}
The onset of tunnel scour beneath offshore pipelines has been previously documented to result from a phenomenon known as piping, in which the hydrodynamic pressure difference across a pipeline causes a sufficient pressure gradient within the soil under the pipe to result in floatation or suspension of downstream sediment particles. The change in propensity for onset of tunnel scour due to sedimentation around the pipe has also been previously noted. This paper explores the potential for predicting the cumulative sedimentation around a pipeline in unidirectional currents using a more fundamental approach than has previously been described in the literature. The results of this approach are compared to model pipeline experiments to see how well the predictions explain the observed changes in sedimentation and the associated effects of sedimentation on the potential for tunnel scour.
\end{abstract}

\section{INTRODUCTION}

\subsection{Motivation}

The motivation for this work arose as a result of a research project investigating the onset of scour under pipelines which feature geometric irregularities such as field-joints (Griffiths et al., 2016). The testing was undertaken using UWA's new Small O-tube recirculating wave / current flume where the closedloop form of the facility enables scour testing to be performed in the presence of a continuous upstream sediment supply. While the tests generated useful observations, in many tests the presence of varying levels of sedimentation around the pipe was observed and appeared to have influenced the potential for onset of scour. Some tests resulted in the complete burial of the pipe without any tunnel scour, as shown in Figure 1.

The motivation for this work was, therefore, to explore the extent to which the sedimentation around the pipe could be predicted and, thence, accounted for in the prediction of scour onset.

The research reported in this paper forms part of a background body of work into the behavior of subsea pipelines when placed onto erodible seabeds. This ongoing research program includes work being undertaken within the STABLEpipe JIP, with sponsorship by Woodside Energy and Chevron and with JIP participation by UWA and Wood Group Kenny. A number of other prominent industry organisations and technical authorities have also contributed to the
JIP, whose primary aim is to generate new engineering guidance enabling the effects of mobile and erodible seabeds to be captured in design. The scope of this JIP is described by Griffiths et al. (2010) with the new design paradigms described by Fogliani et al. (2013). The cornerstone of this JIP is physical modelling of the tripartite interactions between pipes, mobile seabed soils and the fluid forcing by waves and currents using the world-unique UWA Otube test facilities. Useful insights into the nature of this research are also described by Draper et al. (2015).

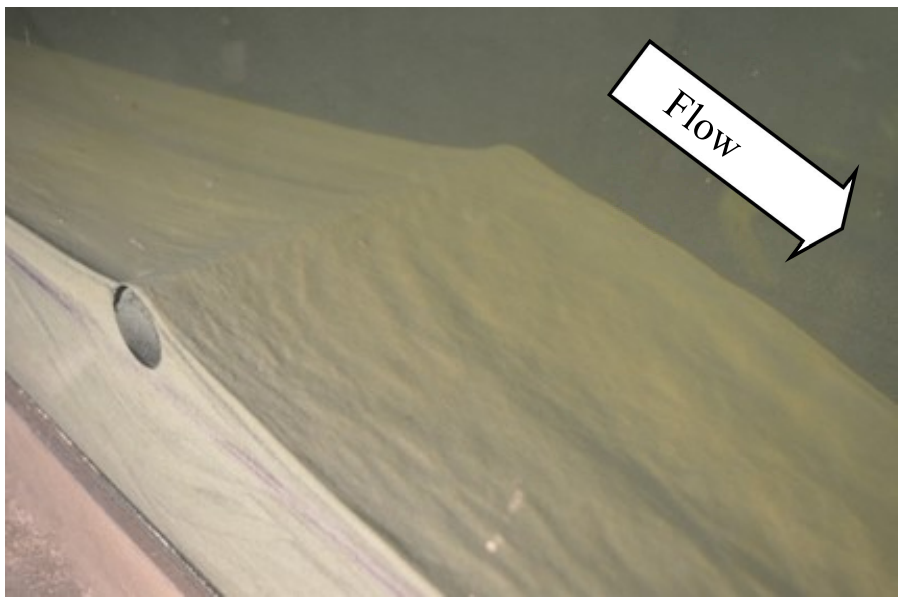

Figure 1 Effect of Sedimentation on Scour Onset 


\subsection{Existing Models for Prediction of Scour Onset}

The initial formation of pipeline spans is important to predicting their subsequent morphology and can arise either through the irregular profile of the seabed leading to pipe non-conformity and gaps, or through the initiation of tunnel scour by piping. Extensive prior research has been undertaken into the mechanism and occurrence of piping, which has been well summarized by Sumer \& Fredsoe (2002). Under steady currents the onset of piping can be predicted using the following empirical formula (Sumer et al., 2001):

$$
\frac{U_{c r}^{2}}{g D(1-n)(s-1)}=0.025 \exp \left[9\left(\frac{e}{D}\right)^{0.5}\right]
$$

where $U_{c r}$ is the critical steady current velocity required to cause piping (referenced at the elevation of the top of the pipe); $g$ is gravity; $D$ is the pipe hydrodynamic diameter; $n$ is the porosity of the sediment; $s$ is the specific gravity of the sediment grains; and $e$ is the embedment of the pipeline into an otherwise flat seabed.

\subsection{Effect of Flume Blockage Ratio on Scour Onset}

The authors' plain pipe test results (Griffiths et al., 2016) are compared to the predictive formula given in Eq. (1) as shown in Figure 2. It may be observed that the results show a reduced propensity for piping compared to the results published by Sumer et al. (2001). The reason for this is likely to be because the present experiments were conducted at a blockage ratio (pipe diameter to flume depth) of between 1/10 and $1 / 6$, whilst the experiments reported in Sumer et al. (2001) were performed mostly at a blockage of $1 / 3$. Zang et al. (2009) has shown that blockage alters the pressure difference either side of the pipeline and the potential for onset of scour due to piping.

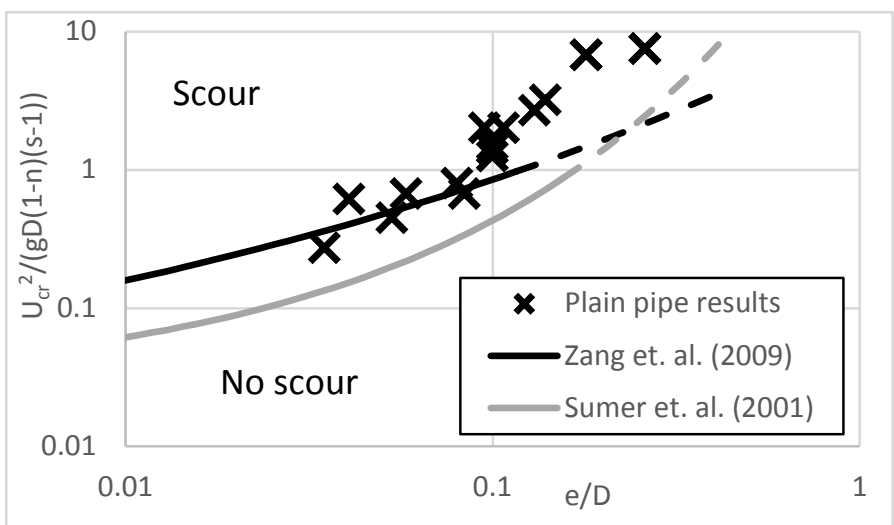

Figure 2. Comparison of Griffiths et al. (2016) Plain Pipe Test Results with Sumer et al. (2001) and Zang et al. (2009) for Blockage 1/10.
The prediction of critical conditions for onset of scour due to Zang et al. (2009) at a blockage of 1/10 is given by the relationship below:

$\frac{U_{c r}^{2}}{g D(1-n)(s-1)}=0.006 \exp \left[7.5\left(\frac{e}{D}\right)^{0.18}\right]$

This relationship is also shown in Figure 2 and is found to agree reasonably well with the present experimental results for the shallowly-embedded pipes considered by Zang et al. less than around $e / D=$ 0.1 , although it is noted the experimental results in this work extend beyond the range considered by either Sumer et al. (2001) or Zang et al. (2009).

\subsection{Effect of Sedimentation on Scour Onset}

A number of researchers undertaking investigations into the onset of scour have noted that some of their tests resulted in lee sedimentation choking the onset of scour, including Chiew (1990) as per Figure 3. This phenomenon has been further investigated experimentally by Zhang et al. (2013) in UWA's miniO-tube. It was found that by defining an equivalent embedment as per Figure 4, which is based on the premise that as lee sedimentation and luff scour lead to migration of the upstream and downstream soil contact points on the pipe, that piping will still occur under conditions with limited upstream sediment supply when the equivalent embedment defined in Figure $4 \mathrm{~b}$ reaches the critical condition predicted by Eq (1), with the time-evolution of effective embedment shown in Figure 5. The same approach is adopted in this work of defining embedment as the equivalent value from Figure $4 \mathrm{~b}$.

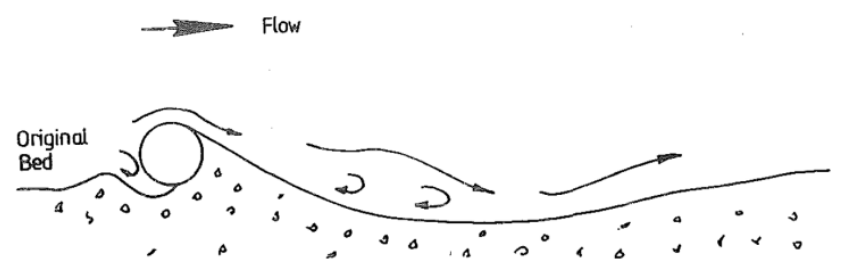

Figure 3 Lee Sedimentation Choking Scour Onset (Chiew, 1990)

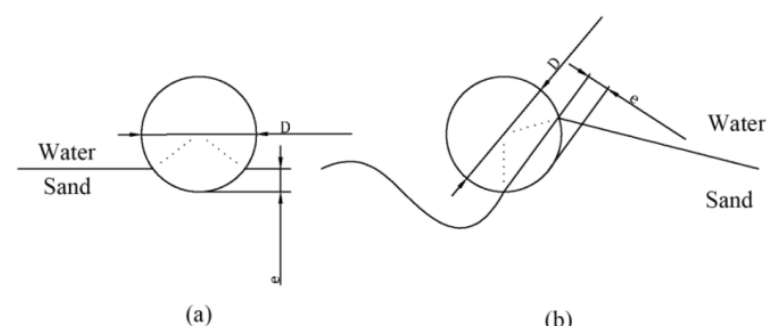

Figure 4 Definition of Embedment (Zhang et al., 2013) 


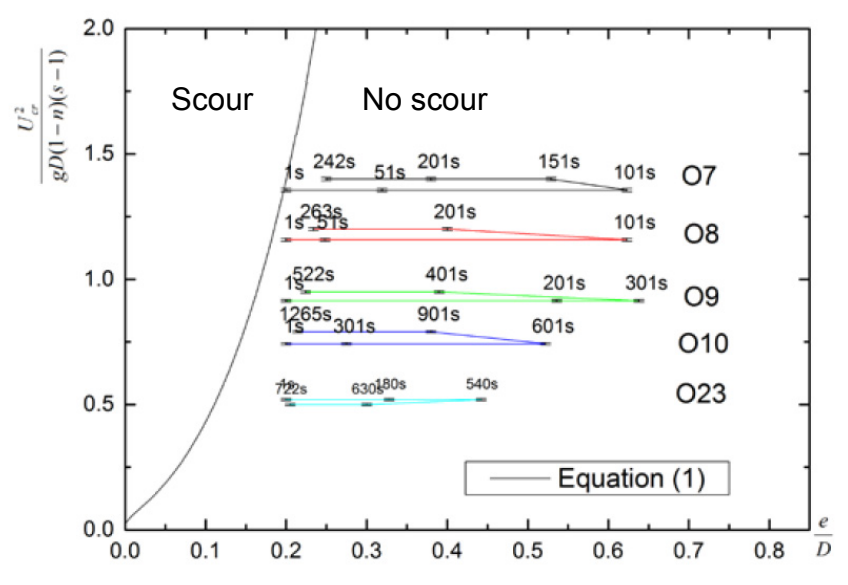

Figure 5 Evolution of Embedment Leading to Scour Under Lean Supply Conditions (Zhang et al., 2013)

Note: Eq (1) in Figure 5 is the same as Eq (1) in this paper.

\section{PHYSICAL MODEL TESTS}

\subsection{Experimental Arrangement}

UWA is host to a set of unique closed-circuit recirculating wave and current flumes for modelling fluid-structure-seabed interaction, as previously described by An et al. (2013) and Cheng et al. (2014). The experimental testing in this work has been undertaken using the new Small O-tube (SOT) and test conditions are described further in Griffiths et al. (2016).

The model pipes used were $30 \mathrm{~mm}$ and $50 \mathrm{~mm}$ diameter and made from transparent solid polycarbonate round bar, machined to fit tightly across the SOT test section. The distance from seabed to lid was $300 \mathrm{~mm}$ giving a blockage ratio of $1: 10$ to $1: 6$ for no pipe embedment. The width of the test section is also $300 \mathrm{~mm}$, giving the same ratios for $L / D$.

The sand used was a siliceous sand with a narrow grading and $d_{50}$ of $0.24 \mathrm{~mm}$. The particle specific gravity was 2.65 , average porosity $40 \%$ and coefficient of uniformity 1.77 . The onset velocity for farfield seabed mobility $U_{\text {sed }}$ is $0.248 \mathrm{~m} / \mathrm{s}$. The full length of the SOT test section was filled with sand. The closed-loop form of the SOT, therefore, results in continual upstream supply of sediment as sand is lost from the outlet of the test section and returned to the inlet, with the total volume of sand conserved in the system. This results in a richer upstream supply than the alternative of using just a short sand-tray in the vicinity of the model pipe. Experience in the use of this facility has enabled testing practices to be adopted which pre-seed the return pipework with an approximately equilibrium volume of sand, minimizing the variation in inlet sediment supply with flow velocity or time.

Steady currents were investigated in the experiments, measured using an ADV at the elevation of the top of the model pipe. The tests were undertaken by rapidly increasing the flow to the 'initial' flow velocity over 5-10 s followed by incremental stepincreases in velocity typically applied at $5 \mathrm{~s}$ intervals by control of the SOT motor rotational speed.

\subsection{Experimental Results}

The $30 \mathrm{~mm}$ and $50 \mathrm{~mm}$ diameter pipe scour experiment results are summarized in Table 1 . The results have been classified into 3 groups based on the extent of sedimentation observed to occur prior to scour onset. These groups are shown in Figure 6, where $U_{c r}$ is the measured velocity at onset of scour and $U_{p c r}$ is the predicted onset using Eq (2) based on initial embedment.

While the ratio of $U_{p c r} / U_{\text {sed }}$ appears to be the primary differentiator between which group the results lie in, the velocity ramp rate is also considered likely to be important and is investigated further below.

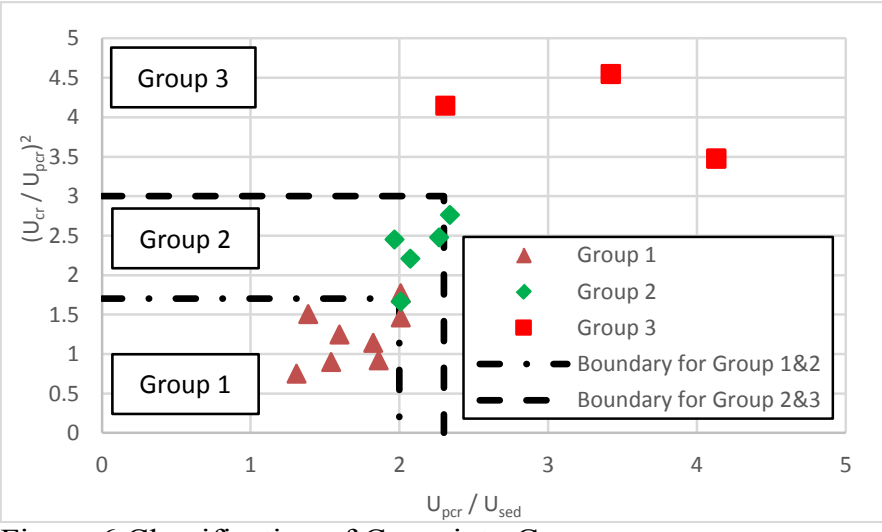

Figure 6 Classification of Cases into Groups

Group 1: The first group experienced little or no sedimentation prior to onset of scour as shown in Figure 7 with the results compared to the predictions of Zang et al. (2009) in Figure 8. Also shown are the thresholds for far-field sediment mobility for the 30 $\mathrm{mm}$ and $50 \mathrm{~mm}$ model pipes. This plot shows that as the velocity increases from zero there is no appreciable change from the initial embedment due to either sedimentation or scour, despite all of these tests exceeding the threshold for far-field seabed mobility just before tunnel scour onset.

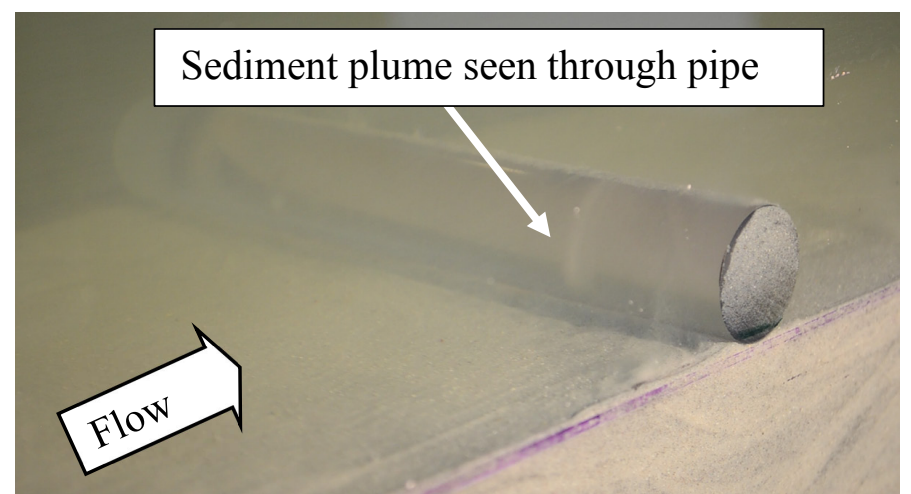

Figure 7 Plume of Sediment Ejected at Onset of Scour (Case 55) 
Table 1 Test Details

\begin{tabular}{|c|c|c|c|c|c|c|c|c|c|c|}
\hline \multirow[b]{2}{*}{ Case } & \multirow[b]{2}{*}{$\begin{array}{c}\text { Initial } \\
\text { e/D }\end{array}$} & \multirow[b]{2}{*}{$\begin{array}{c}\mathrm{D} \\
{[\mathrm{mm}]}\end{array}$} & \multirow{2}{*}{$\begin{array}{c}\text { Initial } \\
\text { Velocity } \\
{[\mathrm{m} / \mathrm{s}]}\end{array}$} & \multicolumn{3}{|c|}{ Time to Reach } & \multirow[b]{2}{*}{ Group } & \multirow{2}{*}{$\begin{array}{c}\text { Scour } \\
\text { Onset Velocity } \\
{[\mathrm{m} / \mathrm{s}]}\end{array}$} & \multirow{2}{*}{$\left(\frac{U_{c r}}{U_{p c r}}\right)^{2}$} & \multirow{2}{*}{$\frac{U_{p c r}}{U_{\text {sed }}}$} \\
\hline & & & & $\begin{array}{c}\text { Initial } \\
\text { Velocity } \\
{[\mathrm{s}]}\end{array}$ & $\begin{array}{c}\text { Scour } \\
{[\mathrm{s}]}\end{array}$ & $\begin{array}{l}\text { Live- } \\
\text { bed }[\mathrm{s}]\end{array}$ & & & & \\
\hline $53^{(1)}$ & 0.095 & 30 & 0.36 & 8 & 60 & 5.5 & 2 & 0.763 & 2.45 & 1.97 \\
\hline 54 & 0.053 & 30 & 0.36 & 6 & 9 & 4.1 & 1 & 0.361 & 0.90 & 1.54 \\
\hline 55 & 0.058 & 30 & 0.32 & 8 & 20 & 6.2 & 1 & 0.442 & 1.25 & 1.60 \\
\hline 56 & 0.041 & 30 & 0.10 & 3 & 89 & 42.2 & 1 & 0.422 & 1.50 & 1.39 \\
\hline 57 & 0.107 & 30 & 0.40 & 8 & 75 & 4.9 & 2 & 0.763 & 2.21 & 2.07 \\
\hline 58 & 0.135 & 30 & 0.60 & 10 & $80^{(2)}$ & 4.1 & 3 & 1.165 & 4.14 & 2.31 \\
\hline 59 & 0.139 & 30 & 0.68 & 7 & 45 & 2.5 & 2 & 0.964 & 2.76 & 2.34 \\
\hline 60 & 0.080 & 30 & 0.40 & 9 & 11 & 5.5 & 1 & 0.482 & 1.14 & 1.82 \\
\hline 61 & 0.084 & 30 & 0.40 & 7 & 12 & 4.3 & 1 & 0.442 & 0.92 & 1.86 \\
\hline 62 & 0.130 & 30 & 0.68 & 8 & 35 & 2.9 & 2 & 0.884 & 2.47 & 2.27 \\
\hline 63 & 0.035 & 30 & 0.16 & 3 & 39 & 28.8 & 1 & 0.281 & 0.75 & 1.31 \\
\hline 64 & 0.100 & 30 & 0.20 & 6 & 120 & 17.9 & 2 & 0.643 & 1.66 & 2.01 \\
\hline 65 & 0.100 & 30 & 0.40 & 9 & 60 & 5.5 & 1 & 0.602 & 1.46 & 2.01 \\
\hline 66 & 0.100 & 30 & 0.50 & 11 & 42 & 5.4 & 1 & 0.663 & 1.77 & 2.01 \\
\hline 67 & 0.180 & 50 & 0.20 & 6 & 223 & 12.2 & 3 & 1.807 & 4.54 & 3.42 \\
\hline 68 & 0.180 & 50 & 1.20 & 25 & 60 & 5.1 & 3 & 1.807 & 4.54 & 3.42 \\
\hline 69 & 0.260 & 50 & 1.41 & 17 & 46 & 3.0 & 3 & 1.908 & 3.47 & 4.13 \\
\hline 70 & 0.260 & 50 & 1.61 & 18 & 38 & 2.8 & 3 & 1.908 & 3.47 & 4.13 \\
\hline
\end{tabular}

Notes:

1. Cases are numbered from 53 because preceding cases reported in Griffiths et al. (2016) were for pipes featuring geometric irregularities such as field joints.

2. Case 58 was halted once the pipe became fully buried. In hindsight this test should have been continued, with the retrospective expectation that scour would still have initiated at a higher velocity. On the basis of this expectation (subject to confirmation with further planned SOT tests), Case 58 has been classified as Group 3.

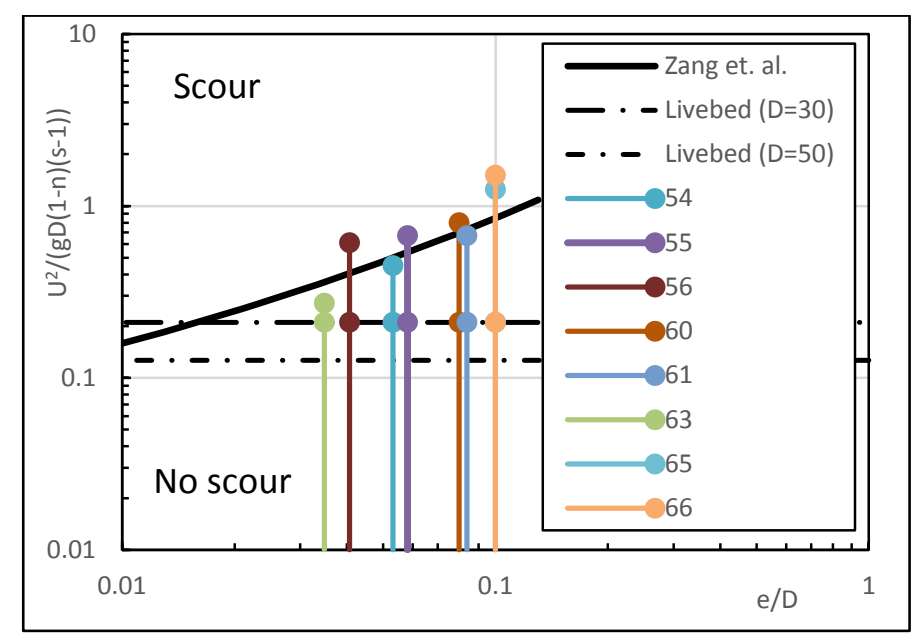

Figure 8 Scour Onset Without Sedimentation

Group 2: The second group of tests experienced some limited sedimentation as shown in Figure 9. It is assumed that as per the results of Zhang et al. (2013) as shown in Figure 4b the effective embedment can be determined from the swept angle of soil contact as indicated on Figure 9, despite the seabed either side of the pipe no longer being flat. The results for this group are shown in Figure 10, with sedimentation typically occurring only just before scour would have been expected to occur. When scour occurred, it typically did so within around 1 second of the increased embedment due to sedimentation beginning to reduce again - these results, therefore, appear to be quite sensitive to test conditions as to when scour will occur depending on the extent to which sedimentation delays the onset.

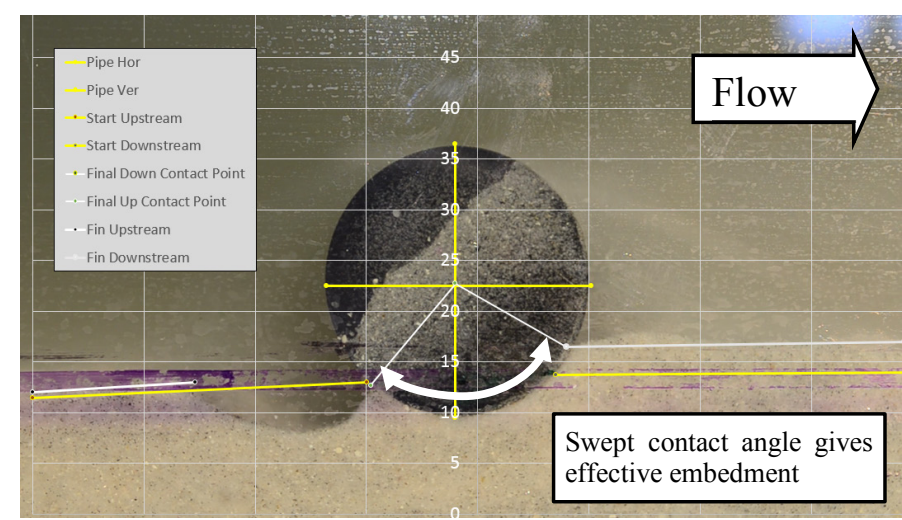

Figure 9 Limited Sedimentation Prior to Scour (Case 64) 


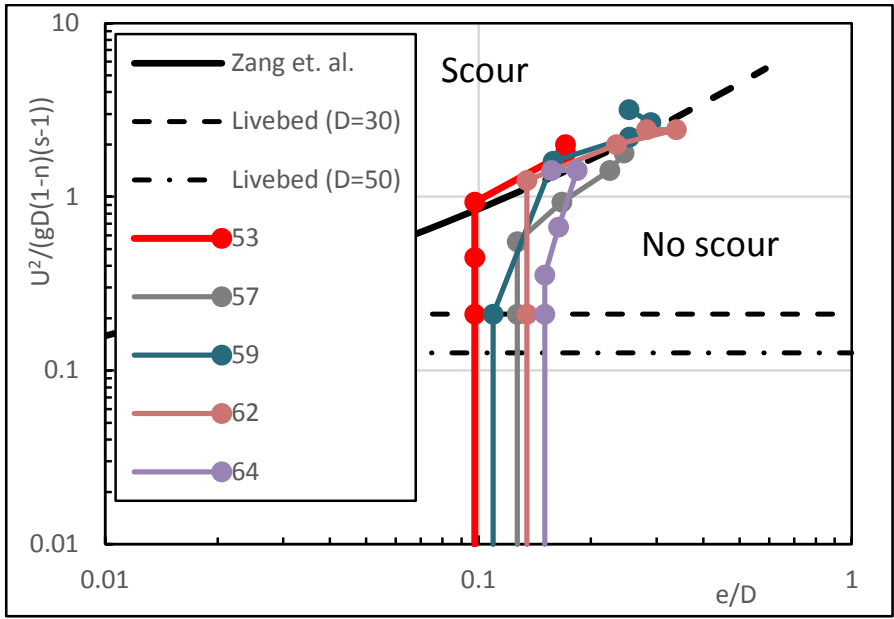

Figure 10 Scour Onset With Some Sedimentation

Based on qualitative observations from the testing, the results may also be sensitive to whether the upstream sediment supply rate is 'rich' or 'lean' (which depends on how much sand was deposited in the Otube return pipework during the previous test). It is also worth noting that the testing procedure applied was to pick an initial velocity which was just below the point at which scour onset was expected, then to step the current up more slowly thereafter to try and accurately determine the point of onset of scour, while minimizing the effect of sedimentation. As a result of this procedure it is expected that as shown in Figure 10 and Figure 11 many of the cases came very very close to scour onset immediately.

Group 3: The final group of tests display significantly more complex behaviour. They have all run slow-enough compared to the rate of sedimentation that the sediment profile has largely reached equilibrium around the pipe before rapid deburial takes place. The deburial and onset of scour appears to occur at a constant threshold velocity which does not depend (within the range of test parameters considered) on the initial embedment, ramp rate or pipe diameter. As shown in Figure 11 they all exhibit an almost linear progression towards piping followed by an increasingly rapid sedimentation phase. Then a characteristic 'hook turn' occurs and rapid deburial leads to scour onset.

The temporal evolution of this is shown in Figure 12 for Case 69, with photographs of the evolution of sedimentation included in Figure 28 in the Appendix.

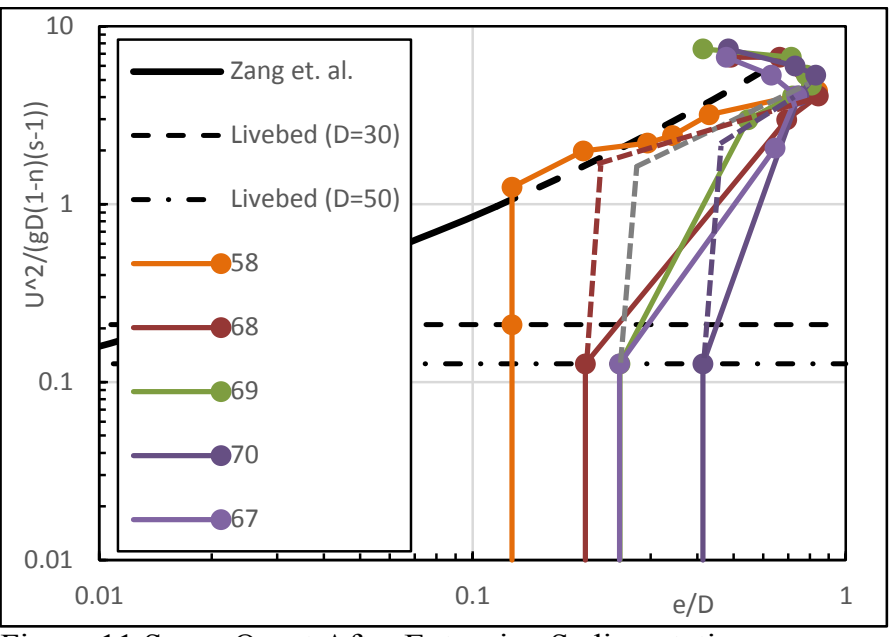

Figure 11 Scour Onset After Extensive Sedimentation (Note Case 58 was halted prior to onset of scour)

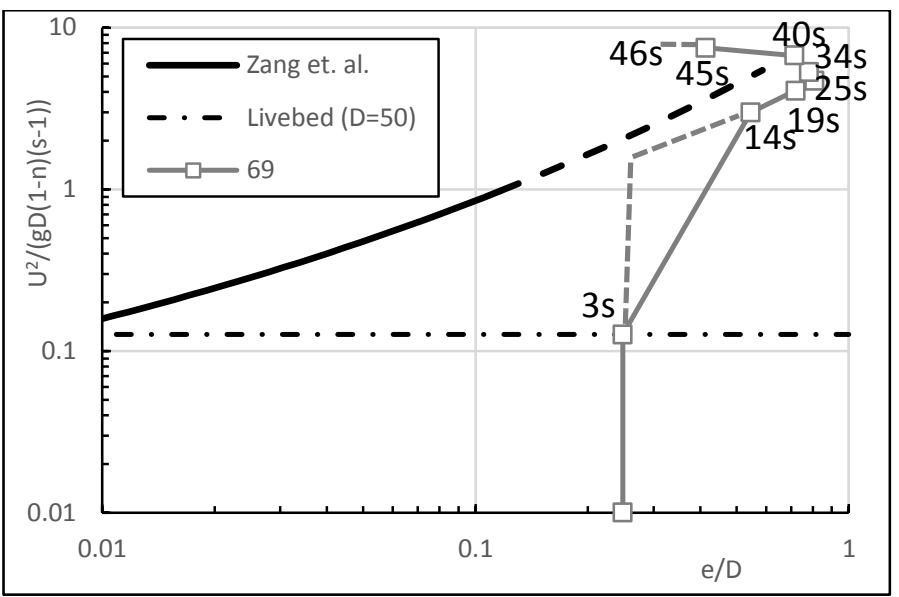

Figure 12 Time Evolution of Embedment Leading to Scour (Note the dashed lines in the figure above suggest the path we believe the effective embedment follows, however the use of sand wedges against the test section wall to control end effects obscured a clear view of this part of the behaviour)

These photographs show that lee sedimentation forms very quickly, followed by luff sedimentation which leaves the pipe almost fully buried. This is followed by very rapid onset of luff scour which progresses past the initial seabed level until onset of scour occurs.

By defining the lee and luff soil contact angles against the pipe as shown in Figure 13, the evolution of lee versus luff sedimentation / scour can be seen in Figure 14. This indicates that lee sedimentation appears to be limited to around $140^{\circ}$ and luff sedimentation to $130^{\circ}$. 


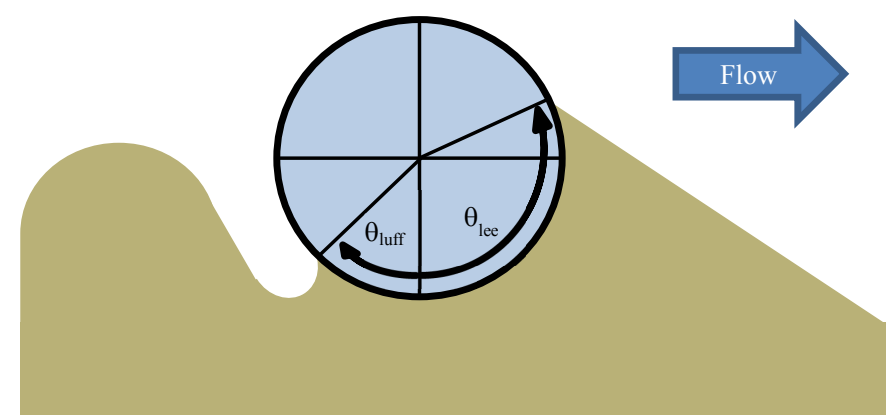

Figure 13 Definition of Soil Contact Angles

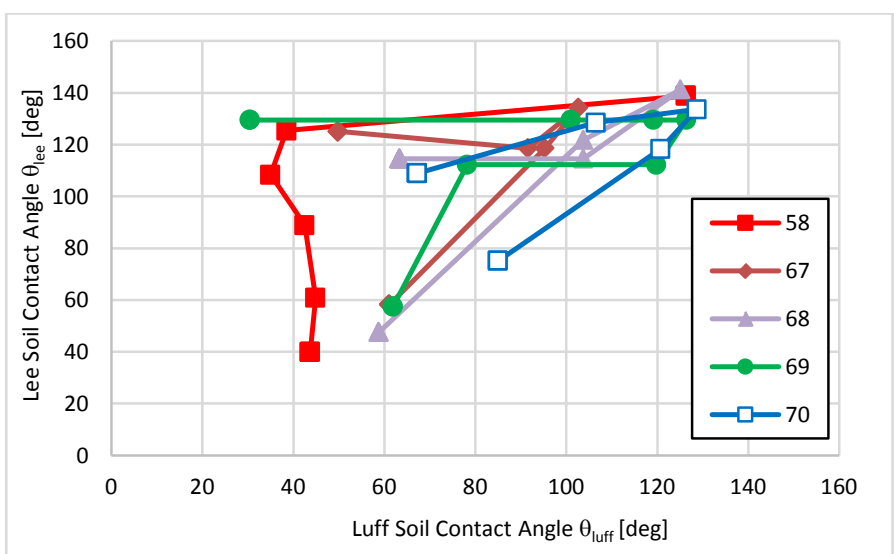

Figure 14 Paths of Group 3 Soil Contact Angles

While commencing from a wide range of initial e/D values, it is noted that the Group 3 tests all seem to have scoured at a constant critical velocity of $7.5=U_{c r}{ }^{2} /(g . D \cdot(1-n) \cdot(s-1))$. Extrapolating using Eq (2) this equates to a relative embedment $e / D=0.76$. It would be of great interest to extend the range of relative embedments tested to see at what point this behaviour ceases. However if scour onset on an erodible seabed becomes insensitive to initial embedment then we can solve to give a critical velocity as a function of $D$, as shown in Figure 15.

This suggests that we can solve to find a limiting SG for pipe stability above which pipes on erodible seabeds should be stable and that this is insensitive to their initial embedment. Taking a very simplistic approach of $\rho_{w}=1025 \mathrm{~kg} / \mathrm{m}^{3}, C_{D}=0.7, C_{L}=0.9, \mu$ $=0.6$ we can solve to give an upper-bound required SG of 10.8 which is constant with $D$ and insensitive to initial $e / D$. While this is higher than practical to be of significant real project interest, it is noted that this does suggest a cap on the otherwise asymptotic required SG for stability of cables where the submerged weight decreases with $1 / D^{2}$ while the hydrodynamic forces decrease with $1 / D$.

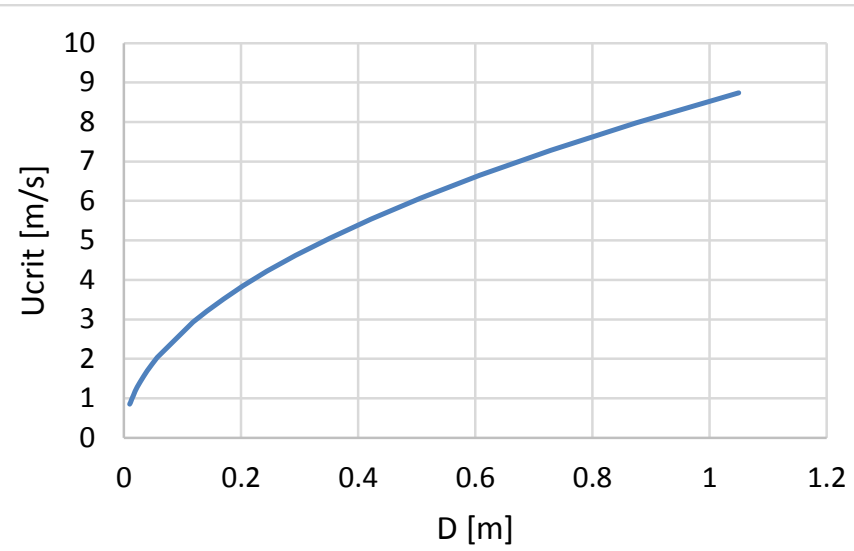

Figure 15 Critical Velocity for Scour Onset vs Diameter

\section{EXPLORATION OF SEDIMENTATION}

\subsection{Sedimentation Model}

Based on observation of sediment transport pathways during testing, a relatively rudimentary sedimentation model is proposed which differs to those previously presented, including Zhang (2013), Leckie et al. (2016) and Mohr et al. (2016). The approach taken is shown schematically in Figure 16 where the predicted transport of sediment is used to estimate the accumulation or loss of soil volume in the lee and luff areas.

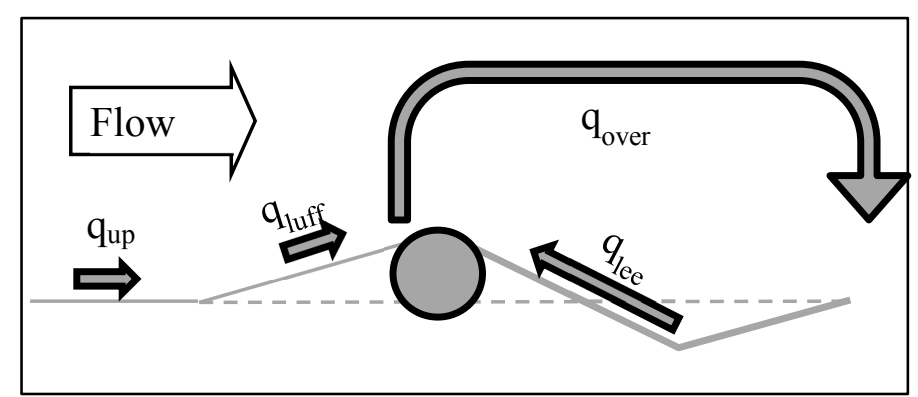

Figure 16 Sedimentation Model Schematic

It is assumed incoming sediment from upstream occurs from bedload transport following the approach by Soulsby (1997) where the rate is given by

$$
\Phi=12 \theta^{\frac{1}{2}}\left(\theta-\theta_{c r}\right)
$$

Where $\theta$ is the Shield's Parameter of the flow, $\theta_{c r}$ the critical Shield's number for onset of soil motion and $\Phi$ is the dimensionless bedload transport rate given by

$\Phi=\frac{q_{b}}{\left[g(s-1) d_{50}{ }^{3}\right]^{1 / 2}}$

Where $q_{b}$ is the volumetric transport rate per unit width and $d_{50}$ is the median particle size by weight. The transport of suspended sediment from upstream is ignored, hence only incoming bedload transport is assumed. 
Noting from test observations that the incoming sedimentation from upstream tends to form an inclined bank on the luff-side of the pipe as shown in Figure 16, the formation of this luff ramp is modelled by integrating the difference between $\mathrm{q}_{\mathrm{up}}$ and $\mathrm{q}_{\text {luff }}$ to give the increase in soil volume of the ramp. Assuming a constant ramp length of 5D, the changing height of the ramp with time can be found as can the upstream contact angle as defined in Figure 13.

Soulsby (1997) gives the influence of seabed slope on the critical shear stress in this luff region as

$\frac{\tau_{\beta c r}}{\tau_{c r}}=\frac{\sin (\beta+\phi)}{\sin (\phi)}$

Where $\tau_{\beta c r}$ is the critical shear stress for onset of soil motion on the slope, $\tau_{c r}$ the critical shear stress for onset on a flat bed, $\beta$ is the slope angle in line with the flow (positive up-hill) and $\phi$ is the soil repose angle. This is used to modify the critical shear stress on the luff ramp to account for the changing slope, which leads to a change in $\mathrm{q}_{\text {luff }}$ and therefore contributes to sedimentation. However the seabed shear stress also changes with slope based on the results of CFD modelling summarized in Griffiths et al. (2014) and further analysed in Zhao (2015). For the case of increasing sedimentation around the pipe shown in Figure 17 the profiles of seabed shear stress amplification are shown in Figure 18. The peak values from approximately 1D upstream of the pipe are plotted in Figure 19 as a function of luff seabed slope.

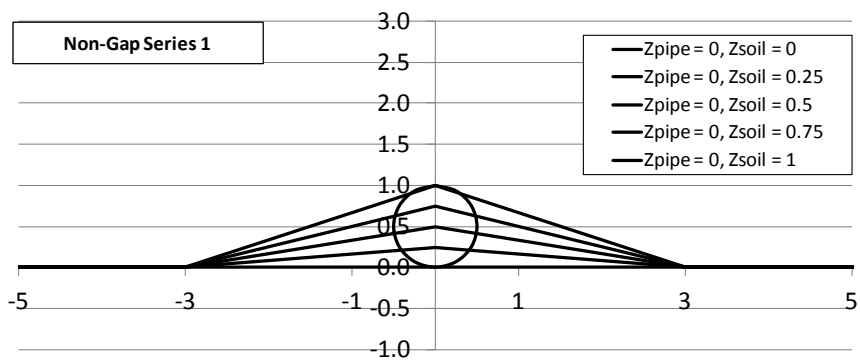

Figure 17 CFD Model of Sedimentation (Griffiths et al., 2014; Zhao et al., 2015)

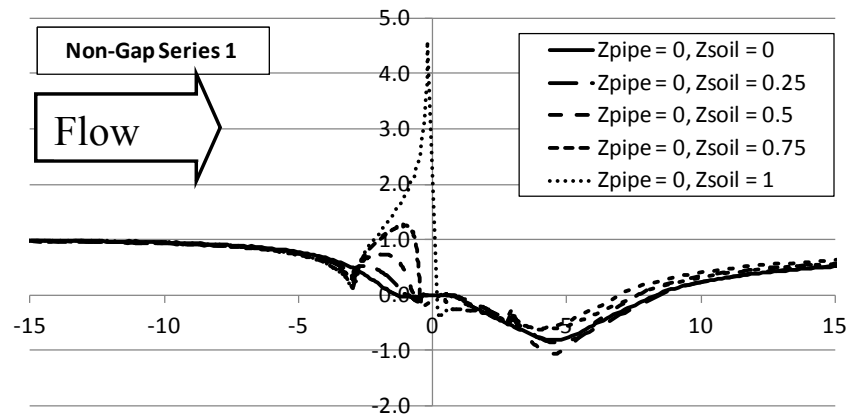

Figure 18 Shear Stress Amplification Profiles (Griffiths et al., 2014; Zhao et al., 2015)

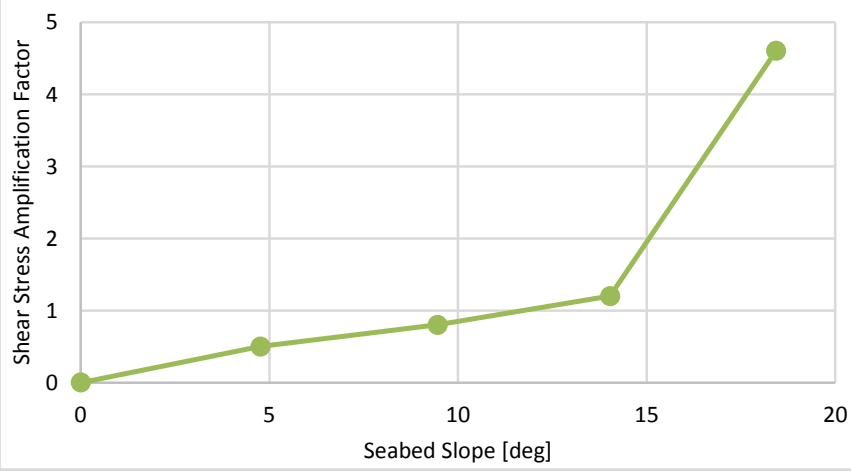

Figure 19 Effect of Sedimentation on Peak Luff Shear Stress Amplification

Combining these two effects, we can define the luff ramp sediment capture efficiency as

Capture efficiency $=1-\frac{\mathrm{q}_{\text {luff }}}{\mathrm{q}_{\text {up }}}$

Which has been plotted as a function of $\tau_{u p} / \tau_{c r}$ in Figure 20.

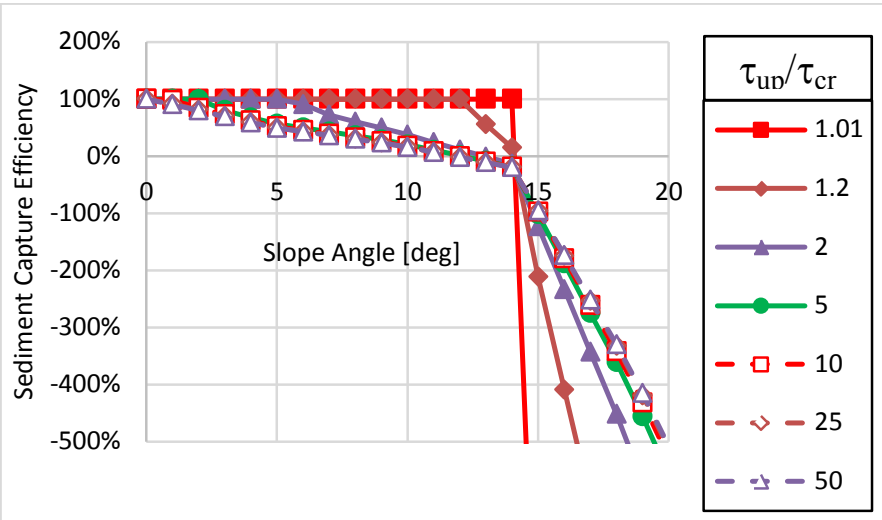

Figure 20 Luff Ramp Sediment Capture Efficiency Versus Ramp Angle and Ratio of Upstream to Critical Shear Stress

There are some interesting observations which can be inferred from the above plot, including that:

- For $\tau_{u p} / \tau_{c r} \approx 1$ the capture efficiency stays at $100 \%$ under constant flow velocity until the pipe is buried and therefore the rate of sedimentation would be predicted to remain linear rather than decaying exponentially;

- For $\tau_{u p} / \tau_{c r}>2$ the capture efficiency decays linearly with embedment under constant flow velocity. Together with the prediction that the change in upstream embedment is proportional to the capture efficiency, therefore the rate of sedimentation would be predicted to decay parabolically;

- Once the sedimentation goes above $e / D=0.75$, a rapid spike in shear stress amplification develops which drives sediment capture efficiency to be strongly negative. While there are many details of this tipping point which need to be better understood, it is remarkable that this prediction 
mirrors the observed rapid deburial at the luff of the pipe as shown in Figure 28 and observed consistently in Group 2 and Group 3 tests.

This differs to the form of rate functions previously used to describe scour and sedimentation, including by Fredsoe (1992) who proposed $S / S o=$ $1-\exp (-t / T)$.

The sedimentation model then assumes that any mobile soil not arrested at the luff ramp is carried over the pipe as suspended sediment and lands downstream beyond the flow reattachment point.

To describe the lee sedimentation against the pipe and associated scour hole located approximately 4D downstream, the model assumes a closed system with redeposition of soil from the scour hole towards the lee of the pipe. Again drawing on Figure 18 the lee sedimentation and scour shear stress amplifications can be extracted and are plotted in Figure 21 and used with the critical shear stress correction for slope from Eq. (5). Unfortunately this approach does not result in a sedimentation model which reaches zero sediment capture efficiency as the slope reaches an equilibrium value, hence the sedimentation has been capped equal to the top of pipe.

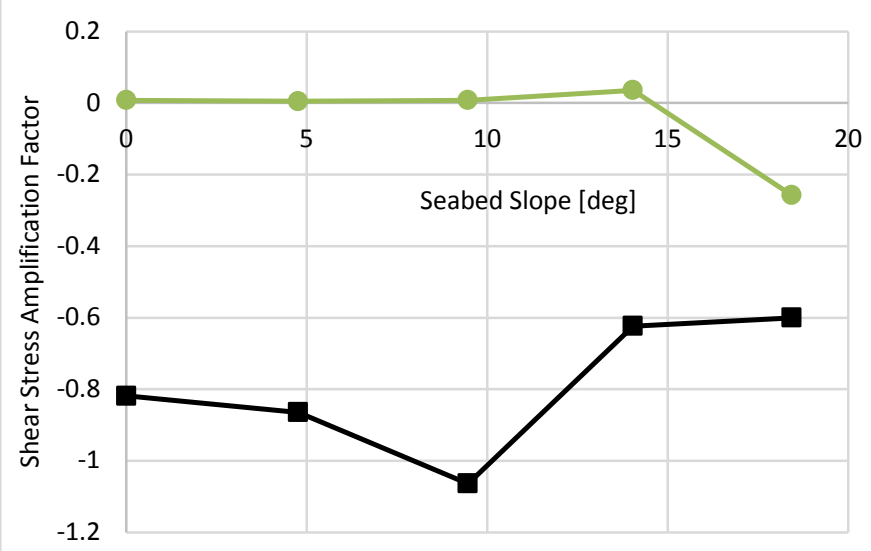

Figure 21 Effect of Sedimentation on Near and Far Lee Shear Stress Amplification

\subsection{Comparison of Sedimentation Model with $\mathrm{O}$ - tube Test Results}

Using the sedimentation model described above comparisons have been undertaken with the O-tube test results for plain pipe. The state of sedimentation as a function of time has been determined by graphical scaling from the video records of each test, as shown in Figure 9. The comparison is presented in Figure 22 for Case 55 (Group 1) and in Figure 23 for Case 58 (which became fully buried as per Figure $1)$.

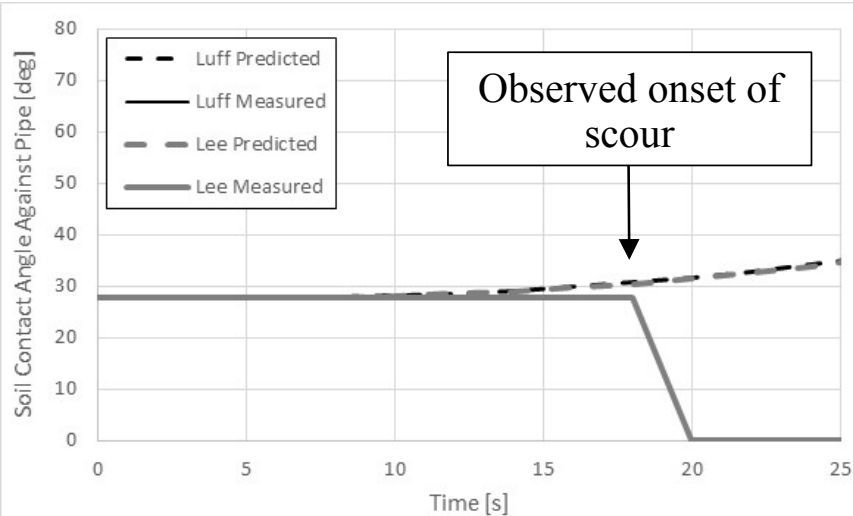

Figure 22 Comparison of Predicted vs Observed Sedimentation for Case 55 (Group 1)

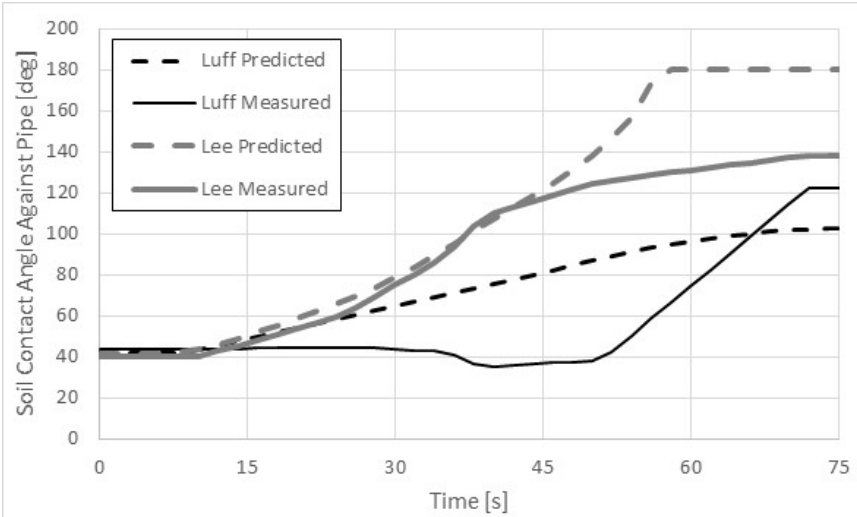

Figure 23 Comparison of Predicted vs Observed Sedimentation for Case 58 (Group 3)

The sedimentation model is therefore observed to:

- Show reasonable levels of accuracy for lee sedimentation up to around $100^{\circ}$ contact angle with the pipe, after which it tends to over-estimate the embedment, noting from Figure 14 that the observed lee sedimentation appeared to reach an upper-bound of around $140^{\circ}$;

- For the luff sedimentation, the model appears to offer a reasonable estimate of the conditions under which minimal sedimentation will occur, but is observed in general to over-estimate the sedimentation once significant upstream transport occurs until equilibrium is reached at $100^{\circ}$ where it under-estimates the observed upperbound of around $130^{\circ}$.

On this basis the sedimentation model offers the opportunity to evaluate and predict when scour onset will be delayed or suppressed due to the occurrence of sedimentation.

It is however noted that there is significant potential to refine the upstream sedimentation model to better account for the observed horizontal-axis luff vortex which is able to transport sediment laterally to the test section walls where horseshoe vortexes lift the sediment into suspension where it can be transported over the pipe and far downstream, as shown from CFD modelling in Figure 24 and from observation of tests as shown in Figure 25. 


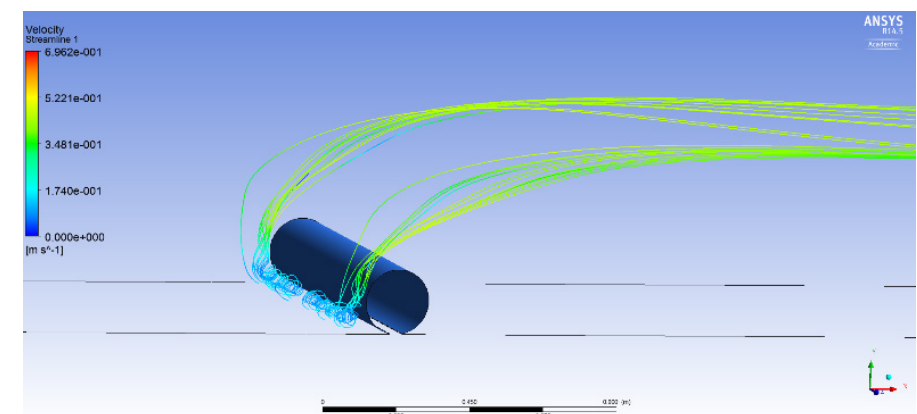

Figure 24: Luff Horizontal Helical and Horseshoe Vortices Formed Against O-tube Side-Walls (Ni, 2013)

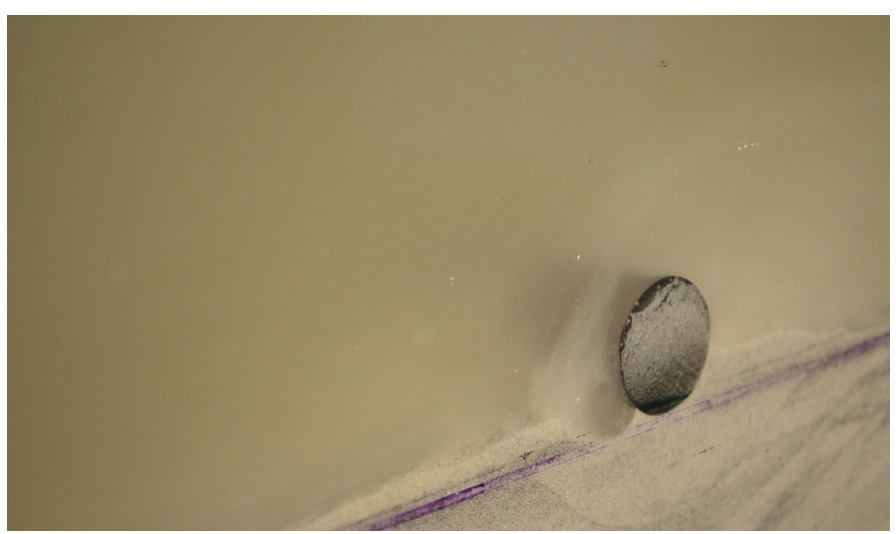

Figure 25: Horseshoe Vortices Observed Against O-tube SideWalls

\subsection{Bifurcation of Scour vs Sedimentation}

The outcome of these experiments is the observation that in many field conditions, the metocean environment will be unable to produce the flow conditions predicted by Figure 15 to be required to cause scour onset after sedimentation has occurred. The expectation under these conditions would be that the pipeline remains embedded and low levels of scour initiation would be expected, leading to a bifurcation in the behavior depending on whether scour is able to initiate prior to sedimentation occuring.

\subsection{Inferences for Field-Scale Conditions}

To explore the inferred implications of these observations on real pipelines, the sedimentation model has been applied to determine the propensity for scour for 3 pipes $-100 \mathrm{~mm}$ representing a typical cable or umbilical, $350 \mathrm{~mm}$ representing a typical infield flowline and $1000 \mathrm{~mm}$ representing a typical gas export trunkline.

These pipelines have been shallowly embedded into erodible soil with typical embedment of $1 \%$ to $7 \%$ for the $100 \mathrm{~mm}$ pipe and $0-3 \%$ for the $350 \mathrm{~mm}$ and $1000 \mathrm{~mm}$ pipes. While these embedments are lower than typically observed average values on sandy soils, it is noted by Westgate \& White (2015) that in as-laid surveys of real pipelines the embedment varies significantly over short distances, with the results of Griffiths et al. (2016) showing that relevant averaging length scales for scour can be less than a diameter. On that basis the embedments are considered suitable for the purposes of this investigation.

The soil properties were then adjusted to give velocity ratios of between 1.01 and 2 for the predicted scour onset without sedimentation to the onset velocity for sediment mobility.

The pipes were then subjected to linearly-ramped unidirectional currents to a sufficient velocity to cause scour. The acceleration of the current was reduced until scour was suppressed by sedimentation, with the results presented in Figure 26. These limiting accelerations are compared to the typical values presented in Table 2 for solitons, semi-diurnal tidal currents and cyclonic storm conditions (where Draper et al. 2015 provides useful cyclonic acceleration data).

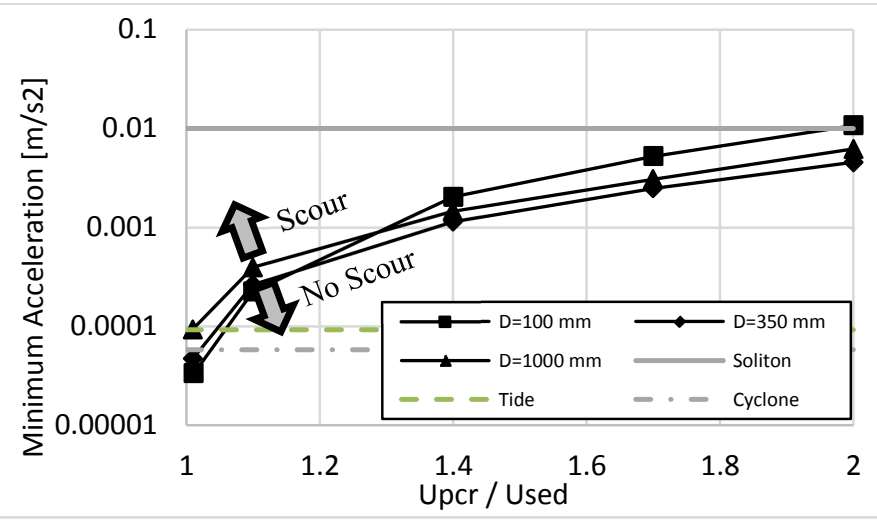

Figure 26 Limiting Acceleration for Scour Onset to Occur

\begin{tabular}{cccc} 
Table 2 & $\begin{array}{c}\text { Typical Metocean Condition Ramp Rates } \\
\text { Near-bed Velocity } \\
\text { Ramp }\end{array}$ & $\begin{array}{c}\text { Ramp } \\
\text { Acceleration } \\
{\left[\mathrm{m} / \mathrm{s}^{2}\right]}\end{array}$ \\
\hline Soliton & 1.0 & $100 \mathrm{~s}$ & 0.01 \\
Tide & 1.0 & $180 \mathrm{mins}$ & $9.3 \mathrm{e}-5$ \\
Cyclone & 2.5 & $12 \mathrm{hrs}$ & $5.8 \mathrm{e}-5$
\end{tabular}

The results of this modelling suggests embedment increased typically by $30 \%$ for the $100 \mathrm{~mm}$ pipe, double for the $350 \mathrm{~mm}$ pipe and 3.5 times for 1000 $\mathrm{mm}$ pipe. As a result of this increased effective embedment due to sedimentation, the onset velocity for scour was increased as shown in Figure 27.

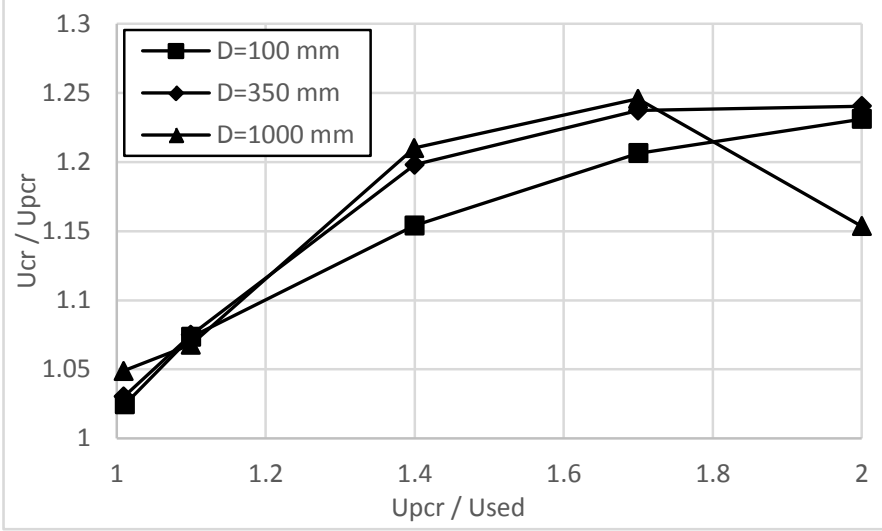

Figure 27 Effect of Sedimentation on Scour Onset Velocity 
The inferred outcomes of these modelling predictions are that:

- The existing published guidance suggests the initial shallow embedment of the pipe and the peak velocity at the top of pipe determine the propensity for scour onset. However it is clear that the phenomenon of sedimentation causes a bifurcation in the scour response of pipelines with only limited sensitivity to diameter. In addition to the above input parameters, the rate of acceleration of the metocean condition and the ratio of predicted scour onset velocity to live-bed velocity appear important;

- Where pipelines are placed on an erodible seabed, unless the ratio of predicted scour onset to live-bed velocity is very low $\mathrm{O}(1.01)$, typical metocean conditions such as tidal currents and storms have inadequate accelerations to prevent sedimentation from suppressing scour;

- Where pipelines are subjected to soliton events, as the metocean condition capable of causing sedimentation and/or scour, scour can occur with limited influence from sedimentation;

- Based on the results of the Group 3 tests, it appears that where metocean conditions are sufficiently strong, even pipes which have reached equilibrium sedimentation can be deburied, although this phenomenon still requires further investigation.

\section{CONCLUSIONS}

It is concluded that there is potential for predicting the cumulative sedimentation around the pipe as a function of prior time-varying uni-directional current flow history using a relatively fundamental approach and that the results of this approach compare usefully with shallowly-embedded model pipe tests of scour onset. While scope exists for further refinement of this approach, it appears useful in determining when sedimentation will result in suppression of scour onset for field conditions.

\section{ACKNOWLEDGEMENTS}

The authors gratefully acknowledge the generous assistance of the STABLEpipe JIP sponsors (Woodside and Chevron) for their support in the development of the UWA O-tube research facilities.

\section{REFERENCES}

An, H., Luo, C., Cheng, L., \& White, D. (2013). A new facility for studying ocean-structure-seabed interactions: The Otube. Coastal Engineering, 82, 88-101.

Cheng, L., An, H., Luo, C., Brown, T., Draper, S., \& White, D. J. (2013). UWA's O-tube facilities: Physical modelling of fluid-structure-seabed interaction. In ICPMG2014-Physical Modelling in Geotechnics: Proceedings of the 8th International Conference on Physical Modelling in Geotechnics 2014 (ICPMG2014), Perth, Australia, 14-17 January 2014 (p. 3). CRC Press.

Chiew, Y. M. (1990). Mechanics of local scour around submarine pipelines. Journal of Hydraulic Engineering, 116(4), 515-529.

Draper, S., An, H., Cheng, L., White, D. J., \& Griffiths, T. (2015). Stability of subsea pipelines during large storms. Philosophical Transactions of the Royal Society of London A: Mathematical, Physical and Engineering Sciences, 373(2033), 20140106.

Fogliani, N. (2013). Australian Sector Review: STABLEpipe JIP Progress Towards Improved Understanding of Pipeline Stability. In Proceedings of the Offshore Pipeline Technology Conference, Amsterdam.

Fredsøe, J., Sumer, B. M., \& Arnskov, M. M. (1992). Time scale for wave/current scour below pipelines. International Journal of Offshore and Polar Engineering, 2(01).

Griffiths, T. J., White, D. J., \& Cheng, L. (2010). Progress in Investigating Pipe-Soil-Fluid Interaction: The STABLEpipe JIP. In The Twentieth International Offshore and Polar Engineering Conference. International Society of Offshore and Polar Engineers

Griffiths,T., Zhao, F., Kalkhoven, M., Shen,W., Xu, M., Zan, Z., Leggoe, J. (2015). Seabed shear stress amplification around subsea pipelines: Part 1, 2D parametric study with currents. In: Scour and Erosion, Proceedings Seventh International Conference on Scour and Erosion, Perth, Western Australia, 2 - 4 December 2014, (eds) Cheng, L., Draper, S. and An, H., CRC Press/Balkema, p.337 - 343.

Griffiths, T., Draper, S., Sun, W., White, D., Cheng, L. (2016). Experimental investigation of the effect of geometric irregularities including field joints on the onset of scour under seabed pipelines in steady currents. In: Scour and Erosion, Proceedings Eighth International Conference on Scour and Erosion, Oxford, United Kingdom, 12 - 15 September 2016, (in pub.)

Leckie, S.F., Mohr, H., Draper, S., McLean, D.L., White, D.J. and Cheng, L. (2016). Sedimentation-induced burial of subsea pipelines: observations from field data and laboratory experiments, submitted to Coastal Engineering

Mohr, H., Draper, S., Cheng, L., \& White, D. J. (2016). Predicting the rate of scour beneath subsea pipelines in marine sediments under steady flow conditions. Coastal Engineering, 110, 111-126.

Ni, D. (2013). 3D CFD investigation of the Large O-Tube facility, Final year CEED thesis completed for the School of Civil \& Resource Engineering, The University of Western Australia.

Soulsby, R.L. (1997). Dynamics of marine sands: A manual for practical applications. Thomas Telford, London. 249pp.

Sumer, B. M., Truelsen, C., Sichmann, T., and Fredsøe, J. (2001) Onset of scour below pipelines and self-burial. Coastal engineering 42(4): 313-335.

Sumer, B. M., \& Fredsøe, J. (2002). The mechanics of scour in the marine environment. World Scientific.

Westgate, Z. \& White, D. (2015) 'Quantifying Spatial Variability of As-Laid Embedment for Subsea Pipeline Design', Proceedings of the $34^{\text {th }}$ International Conference on Ocean, Offshore and Arctic Engineering, OMAE2015-42292

Zang, Z., Cheng, L., Zhao, M., Liang, D. and Teng, B. (2009). A numerical model for onset of scour below offshore pipelines. Coastal Engineering, 56(4): 458-466

Zhang, Q., Draper, S., Cheng, L., An, H., \& Shi, H. (2013). Revisiting Mechanics of Onset of Scour Below Pipelines in Steady Current. In Proceedings of International Conference on Ocean, Offshore and Arctic Engineering, OMAE201311334. 
Zhao, F., Griffiths, T., Shen, W., Draper, S., An, H., Leggoe, J., Carneiro, D. (2015), 'Sediment Attractors: Seabed Shear Stress Shadows Around Subsea Pipelines Cause Net Sediment Accretion', Proceedings of the $34^{\text {th }}$ International Conference on Ocean, Offshore and Arctic Engineering, OMAE2015-41651.

\section{APPENDIX}

Figure 28 Progression of Sedimentation (Case 69)

\section{$14 s$}

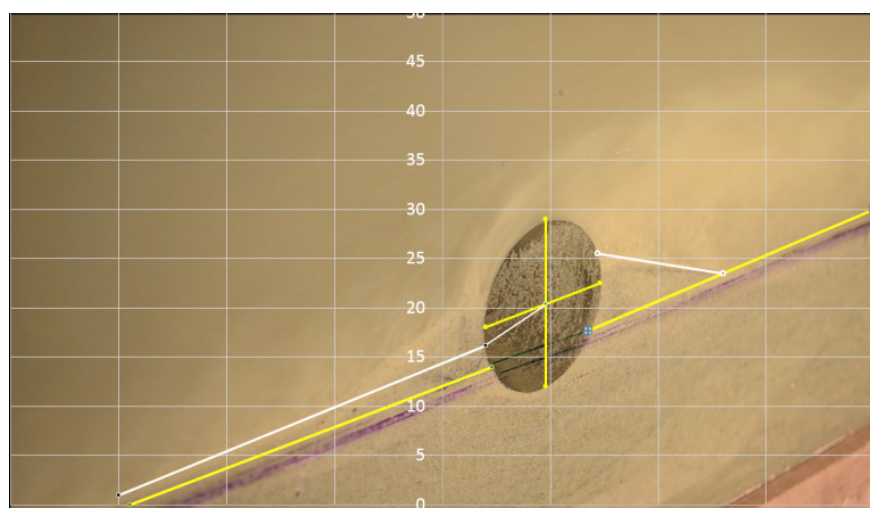

From commencement of the test, livebed conditions were reached at $3 \mathrm{~s}$. After $14 \mathrm{~s}$ the flow has not yet reached the target initial velocity but already significant lee sedimentation has occurred and some slight upstream sedimentation.

\section{9s}

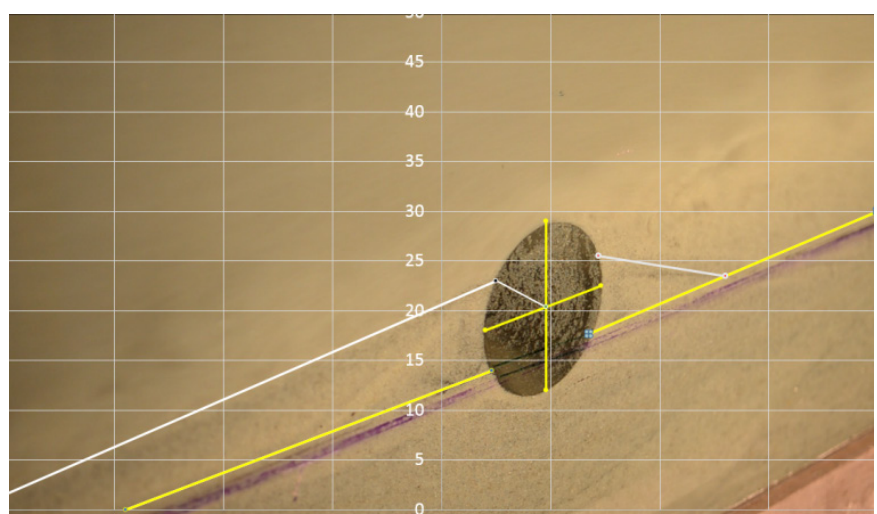

Having reached the target initial velocity at $17 \mathrm{~s}$, the flow acceleration is now lower. The lee sedimentation has not increased appreciably but the luff sedimentation has grown rapidly in height and length.

\section{$25 s$}

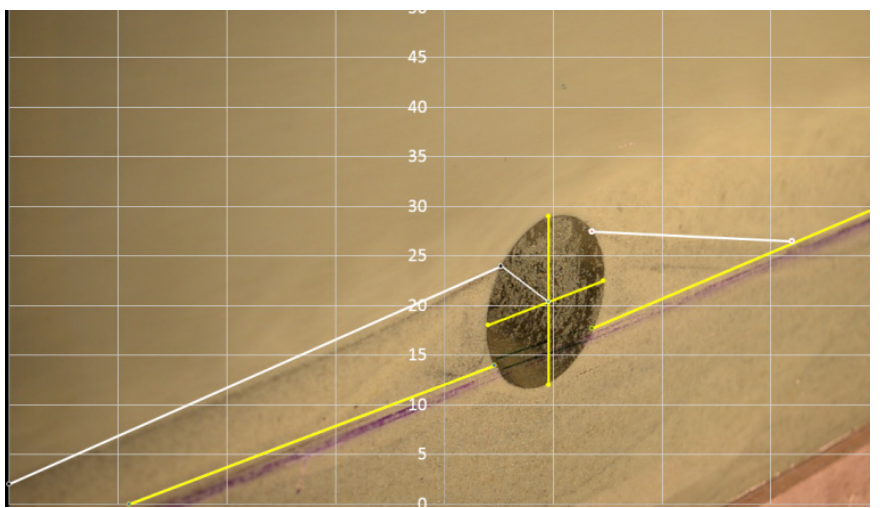

At $25 \mathrm{~s}$ very limited change to the lee or luff sedimentation is observed, despite the flow continuing to be accelerated at a low rate.

\section{$34 s$}

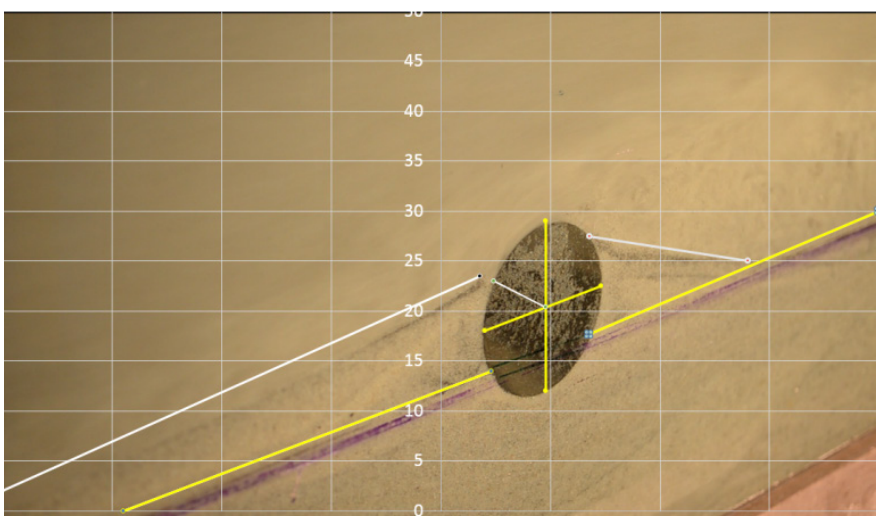

At $34 \mathrm{~s}$ some slight shortening of the lee sediment ramp is observed together with onset of a very small luff vortex.

\section{$40 s$}

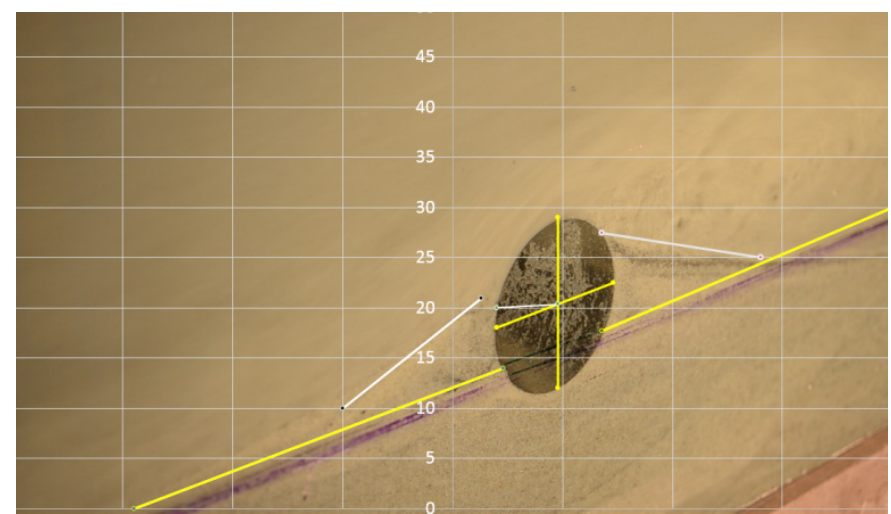

At $40 \mathrm{~s}$ the luff sedimentation is lowering and getting shorter, with the luff vortex clearly visible and associated with a dense sediment plume overtopping the pipe 


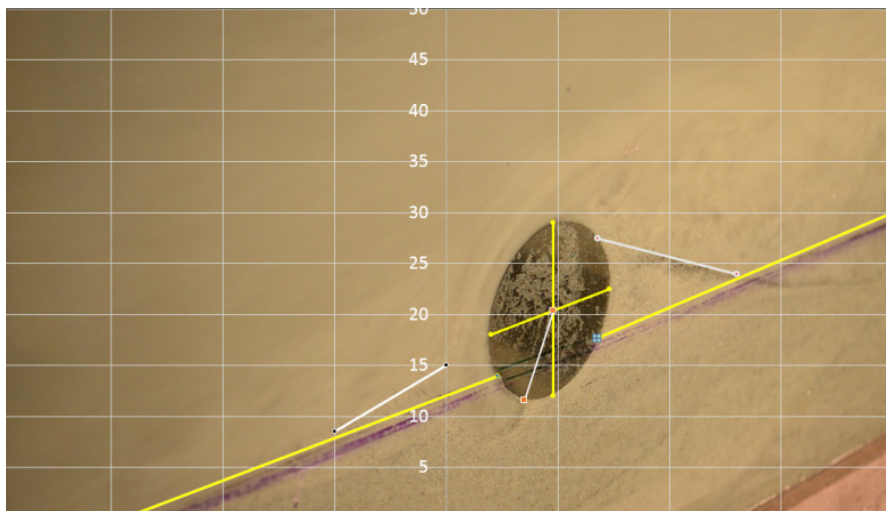

At $45 \mathrm{~s}$ there is rapid progression of luff scour immediately upstream of pipe to below the initial level of the seabed, with rapid lowering of luff ramp. Slight lowering of lee sedimentation

46s

Onset of scour by ejection of the remaining soil plug under the pipe 